\title{
Motivations for Purchasing Luxury Handbags
}

\author{
Yuewei Wei \\ School of Materials \\ The University of Manchester \\ Manchester, M13 9PL, UK \\ Yuewei.wei@manchester.ac.uk
}

\author{
Yi Wang* \\ Sackville Street Building \\ School of Materials \\ The University of Manchester \\ Manchester, M13 9PL, UK \\ yi.wang-2@manchester.ac.uk
}

\begin{abstract}
In 2014, Chinese luxury market accounts for $25 \%$ of whole luxury consumption in the world, becoming the largest luxury market in the world. However, the attitudes and motivations held by Chinese consumers towards luxury products consumption are under-researched, thus becoming an important academic topic, which needs exploration.

Based on a sample of 142 respondents, the research has adopted a multiple regression analysis to explore the potential causal relationships. The conclusion is that income is a statistically significant predictor and the knowledge gap has been greatly narrowed, while education and age do not have significant effects on luxury handbags buying motivations.
\end{abstract}

Keywords - Chinese luxury purchasing; consumer motivation; fashion design

\section{INTRODUCTION}

Most Chinese consumers still prefer to buy luxury handbags from Western countries, there are only about $30 \%$ of Chinese consumers are highly satisfied with the services of these Western luxury retailers, based on a piece of research of Red Luxury [1]. Further, if compared with luxury consumers from developing countries such as Japan or United States, the average age of Chinese consumers much younger [2 and 3]. Therefore, it is necessary to understand contemporary Chinese luxury consumers' behaviours and attitudes, especially for the international luxury retailers who strive to expand market share [4].

This paper will focus on the theory of taste, and investigate whether this theory can fit into fashion consumption research. The concept of taste is defined as cultural patterns of individual choices and preferences [5 and 6].

Based on the theoretical framework, it is naturally expected that Chinese middle class hold different tastes including their attitudes, perceptions or motivations] towards the consumption of luxury products from other classes such as the affluent class. Thus, it is necessary to understand the motivations and attitudes of Chinese consumers in terms of buying luxury products, especially for international luxury retailers who aim to expand the market share of Mainland China.

This research will be conducted in an average Tier 2 city Taiyuan, aiming to understand the luxury goods buying motivations in a Chinese Tier 2 city. There are three research objectives are shown below:
1. To discover whether the income is the main factor to differentiate the luxury handbags buying motivations of upper middle class from the mass middle class' in Taiyuan.

2. To test whether the gap between upper middle class consumers' luxury handbags knowledge and mass middle class consumers' knowledge has been narrowed due to the information explosion in the digital age.

3. To investigate which individual contingent factors such as personal age and education to explain the patterns of luxury handbags consumption motivations of Taiyuan middle class consumers.

The paper starts with a literature review over the relevant topics; it then discusses the development of the hypothesis. The paper will afterwards illustrate the research design and then results and discussion. And finally a conclusion will be provided for the whole paper.

\section{LITERATURE REVIEW}

In the cultural and consumer behavioural sciences, it has been widely assumed and acknowledged that individual behaviours and attitudes may differ across different ethnic groups, cultures and societies [7]. And such differences could be attributed to cultural backgrounds such as linked to national context, ethnic origin, religious affiliation, or education background [8]. The theory of Hofstede [8] has argued that individual behaviours are to a large extent determined by the national culture to which they are aligned rather than simply determined by rational choice theory.

Max Weber also argued that the consumption behaviours could also be differed across different national cultures [9]. For example, consumers from Western countries who were influenced by the Protestant ethic are more likely to develop the spirit of capitalism characterised by a frugal consumption habit and hardworking [10]. Consistent with previous research on the relationship between individual or attitudes and cultural backgrounds, Pierre Bourdieu's [11] has put forward the theory of taste. Warner [12] has stated that the study of taste is concerned with exploration of social relations and dynamics, and how these result in differences in individual perception of social phenomena.

The concept of taste is defined as "cultural patterns of individual choices and preferences" [11]. This definition implicitly assumes that personal preferences in terms of styles 
and types of consumption goods may differ greatly across different cultures [13]. The study of taste is concerned with exploration of social relations and dynamics, and how these result in differences in individual perception of social phenomena, highlighting culture as a primary causal factor such as social class, gender, national culture etc [12].

\section{HYPOTHESIS DEVELOPMENT}

Consumers aligned to a certain social class may have been socialised a particular habitus of consumption [14]. Therefore, consumers who grow up in a certain class may possess a certain pattern or preference of consumption. For example, it has been argued that consumers from high social class are more likely to have a taste, which enables them to appreciate the value of luxury products because of their better education compared with those from low social class [15 and 16].

In this way, Bourdieu has challenged the economic theory of preference, which argues that consumers' preference and choices are completely determined by rational choice theory and supply and demand mechanism [Hollis and Nell, 2008]. Therefore, the Hypothesis 1 and Hypothesis 2 have been proposed below:

Hypothesis 1: Upper middle class consumers are more likely to purchase luxury handbags because of appreciating luxury products' craftsmanship and durability than mass middle class consumers in Taiyuan.

Hypothesis 2: Upper middle class consumers tend to consider that owners of luxury handbags are having good taste.

The most important dimension along which people emulate is property or put in other words economic power [17 and 18]. Once people have enough economic power, they tend to match their social status and also social taste with their economic power [19]. The Hypothesis 3 has been formed as below:

Hypothesis 3: Upper middle class consumers are more likely to purchase luxury handbags to showing personal success and social status.

Some scholars such as Amatulli and Guido [20] and Hung et al. [21] have compared the differences in consumption behaviours between Western and Chinese consumers. Consistent with the taste theory, they argue that the differences have been generated through the distinct socialised values from their own home country. The individualism culture implies individual values [personal taste, self-identity] rather than social values [social recognition], which motivate consumers' luxury goods consumption. On the other hand, since Chinese consumers are characterised by a collective culture, social values such as social recognition are more likely to become the main motivation for the Chinese consumers.

Zheng [22] and Wang et al. [23] indicates that consumers with oversea education background tend to purchase more luxury goods, given all other hedonistic consumption thesis. Therefore, the hypothesis 4 could be formed as shown below:
Hypothesis 4: Consumers with oversea or higher education background are more likely to purchase luxury handbags for self-rewarding.

On the other hand, there are a number of studies which cast doubt on the taste theory. Their key argument is that social class is no longer an important determinant of consumers' taste especially in the context of recent social changes such as globalisation and the rise of Internet. For example, $\mathrm{Li}$ and Kambele [24]'s research has argued that the process of globalisation and industrialisation has increased the diversity of luxury products choices and differentiation level of traditional luxury brands. An increasing number of new American/European/Asian luxury brands have risen, so that the luxury goods in traditional sense no longer only belong to the taste of upper class. Instead, an increasing number of consumers from middle class or even low class could afford different kinds of luxury goods. Therefore, the elitist idea that only the consumers from upper class have good tastes to appreciate the luxury goods should be re-examined. Therefore, the hypothesis 5 could be developed as shown below:

Hypothesis 5: Mass middle class consumers are as knowledgeable on luxury handbags as consumers from upper middle class.

\section{RESEARCH DESIGN}

The questionnaire of this research consists of four parts. In the first part, there are four questions which aim to measure four demographical variables i.e. gender, age, income and education. As discussed in literature review, individual demographic features can to a large extent represent his or her social class. More specifically, gender is measured by a dummy variable with 1 indicating male and 2 female. Age is measured by a continuous variable. Furthermore, education is measured by an ordinal variable with a four-point scale i.e. high school, undergrads, master, and master above. Similarly, income is also measured by an ordinal variable with a 4 point scale i.e. less than 5000 RMB, 5000-9000RMB, 900019000RMB, 19000+RMB.

The second part of the questions includes three questions aiming to measure consumers' luxury handbags buying frequency and their knowledge of luxury products and brands. The extent to which consumers are familiar with luxury products will be measured by number of luxury products bought last year and number of luxury brands known. These two variables are necessary because they represent the extent to which consumers from different social classes are familiar with luxury goods, thus providing a theoretical basis for further analysis of consumers' buying attitudes and motivations.

The third part is consisted of five questions aiming to measure the consumers' attitudes toward luxury handbags and attitudes towards owners of luxury handbags, i.e. whether consumers think luxury handbags of good craftsmanship and durability [question1], customer service [question2], and whether ownership of luxury products indicates a good taste [question3], whether consumers think buying luxury goods is a kind of conspicuous consumption [question4], and whether luxury goods should become a necessary part of life [question5]. These questions aim to test the validity of taste 
theory in a Chinese Tier 2 city Taiyuan, in other words, whether consumers from different social classes hold various attitudes toward luxury handbags [3].

The fourth part is consisted of six questions, which aim to measure consumers' buying motivations of luxury handbags, i.e. consumers buy luxury handbags for a particular designer [question1], for the culture or history of the brands [question2], for showing off their success [question3], for being unique [question4], for social comparison [question5] and rewarding themselves [question6]. These questions are consistent with the aim of the research, which tends to explore the luxury goods buying motivation in light of Bourdieu's taste theory. In other words, the research attempts to explore the extent to which one's social class impacts one's luxury goods buying motivations with other variables controlled.

\section{RESULTS AND ANALYSIS}

The research has used four dimensions to measure the basic patterns of the data, i.e. the maximum, the minimum, the mean, and the standard deviation. The four dimensions lend evidence to the good quality of the data measured by validity and reliability. Specifically, the mean of the income is 2.12 [about 6,000 RMB per month] between the range $1[<5,000 \mathrm{RMB}$ per month] -4 [>19,000 RMB per month], and std. deviation is 0.65 , indicating that different income groups are clearly defined and distributed.

The mean of the gender is 1.69 between the range 1 [Male] -2 [Female], which implies that among the respondents the number of women is larger than that of men, and the std. deviation is 0.46. Also, the mean of age is 3.69 [32 years old], and the std. deviation is 1.59 , which means that the age of respondents is normally distributed. Further, the mean of education is 2.16 , and the std. deviation is 0.92 , which means that the education of respondents is around the university or college level. As shown in Table I, the mean of the frequency of buying luxury handbags is 2.01 [about 3 pieces of luxury handbags per year], and the std. deviation is 0.88 , which indicates a wide range of frequency.

This implies that the frequency of buying luxury handbags is clearly differed across different groups. The mean of the luxury knowledge is 3.61, and the std. deviation is 0.53 , which means relatively narrow range and also implies consumers' knowledge about luxury products is not greatly distinguished between groups. Similarly, the consumers' knowledge of luxury brands has the almost the same pattern with the mean of 3.18 and std. deviation of 0.54 .

. The second part is consisted of 6 questions which aim to measure the buying motivations of luxury products, i.e. the extent to which consumers buy luxury goods for a particular designer or brand, for the culture or history of the brands, for representing their success and social status, for being unique, for rewarding themselves and for social comparison. These questions are consistent with the aim of the research which tends to explore the luxury goods buying motivation in light of Bourdieu's taste theory and to test validity of taste theory in a Chinese Tier 2 city Taiyuan.
TABLE I. RELATIONSHIP TABLE

\begin{tabular}{|c|c|c|c|}
\hline & Frequency & Knowledgeable & Brands Known \\
\hline Education & 0.357 & 0.537 & 0.087 \\
\hline Gender & 0.085 & 0.001 & 0.000 \\
\hline Income & 0.000 & 0.064 & 0.142 \\
\hline Age & 0.124 & 0.000 & 0.000 \\
\hline
\end{tabular}

Based on the Table I, only income is statistically related to buying frequency, as $\mathrm{p}$ value is 0.000 less than 0.05 , which rejects the null hypothesis that there is no relationship between the two variables. It is shown that income has significant statistical relationship with consumers' luxury handbags buying frequency. It indicates that gender and age are statistically related to consumers' luxury products knowledge, as their $\mathrm{p}$ values are all less than 0.05 . There is no statistical relationship between income and consumers' knowledge, as their $\mathrm{p}$ values exceed 0.05.Income is the main factor to determine consumers' social class, there is no obvious gap between consumers' knowledge from different social class.

For the question whether consumers regard luxury goods of high craftsmanship and durability, the statistics shows that social class has partly impacted the consumers' attitudes (seeing Table II). Concerning relationship between craftsmanship and education, the $\mathrm{p}$ value is $0.039<0.05$, which rejects the null hypothesis that there is no relationship between the two variables

TABLE II. RELATIONSHIP TABLE

\begin{tabular}{|c|c|c|c|c|c|}
\hline & $\begin{array}{c}\text { Craftsmanship } \\
\text { and Durability }\end{array}$ & Service & $\begin{array}{c}\text { Good } \\
\text { Taste }\end{array}$ & $\begin{array}{c}\text { Show- } \\
\text { off }\end{array}$ & Necessity \\
\hline Education & 0.039 & 0.229 & 0.006 & 0.045 & 0.098 \\
\hline Gender & 0.265 & 0.003 & 0.046 & 0.078 & 0.143 \\
\hline Income & 0.001 & 0.021 & 0.001 & 0.001 & 0.034 \\
\hline Age & 0.282 & 0.709 & 0.709 & 0.904 & 0.011 \\
\hline
\end{tabular}

More specifically, coefficient is 3.154 indicating a positive relationship, that is, with the increase of education consumers are more likely to regard luxury goods of high craftsman and durability, when other demographic features are controlled. Similarly, for relationship between craftsman and income, the $p$ value is $0.001<0.05$, which rejects the null hypothesis that there is no relationship between the two variables. More specifically, coefficient is 2.457 indicating a positive relationship, that is, consumers who earn high income are more likely to regard luxury goods of high craftsman and durability, when other demographic features are controlled.

In other dimensions of social class i.e. gender and age, this study has not found any statistically significant relationships between social class and luxury goods attitudes. More specifically, for the relationship between craftsman and gender, the $\mathrm{p}$ value is $0.265>0.05$, which fails to reject the null hypothesis that there is no relationship between the two variables, when other demographic features are controlled. 
Similarly, for relationship between craftsman and age, the $\mathrm{p}$ value is $0.282>0.05$, which fails to reject the null hypothesis that there is no relationship between the two variables, when other demographic features are controlled.

Frequency is strongly related to knowledge and brands as the $\mathrm{p}$ values are 0.000 and 0.001 both smaller than or equal to 0.001. This rejects the null hypothesis that there are no relationships between these variables. Also, the coefficients for both are 2.417 and 1.459 which indicate that consumers who buy luxury goods frequently tend to have a good knowledge in terms of luxury brands and also know more brands.

The coefficient of craftsmanship \& durability and of service is 0.022 and 0.320 . It could be demonstrated that the better consumers know about brands, the more they are likely to believe luxury products have good craftsmanship and durability, and luxury brands provide premium quality service.

The attitudes toward consumers owning luxury handbags, the variable craftsmanship and durability of luxury handbags is only strongly related to good taste [p value is 0.000 less than 0.001 ], but not related to the attitude of show-off [p value is 0.301 larger than 0.05]. This result rejects the null hypothesis that there is no relationship between craftsmanship and durability of luxury brands and attitude of having good taste, while the result supports the null hypothesis that there is no relationship between craftsmanship and durability of luxury handbags and the attitude of show-off. Additionally, the coefficient between craftsmanship and durability of luxury brands and attitude of having good taste is 0.023 , which indicates that consumers who believe in luxury handbags' craftsmanship and durability tend to consider owners of luxury handbags have good taste.

Firstly, the variable of representing success and social status is significantly related to the attitude of show-off, as $p$ value is 0.000 less than 0.001 . The result has rejected the null hypothesis that there is no relationship between showing success and social status and the attitude of showing off. Interestingly, the coefficient is -0.187 , which indicates that consumers, who think owners of luxury handbags are showing off, are less likely to purchase luxury handbags for representing personal success and social status.

There are three variables which are statistically related to the motivation of admiring luxury brands' designers. Firstly, the variable of appreciating brands' culture and history is significantly related to the motivation of admiring brands' designers, as $\mathrm{p}$ value is 0.000 less than 0.001 . The result has rejected the null hypothesis that there is no relationship between these variables. Additionally, the coefficient is 0.297, which indicates that consumers, who buy luxury handbags because of admiring brands' designers, are more likely to be motivated by brands' culture and history to purchase luxury handbags.

\section{RESULTS AND DISCUSSION}

The Income is a statistically significant indicator for most dependent variables, which indicates difference between social classes in terms of luxury goods buying motivations and attitudes. This result lends the most direct support to
Bourdieu's taste theory that social class is still a main determinant of individual behaviours. Therefore, it could be seen that income is still the main factor to differentiate the luxury handbags buying motivations of upper middle class from the mass middle class' in Taiyuan.

Moreover, as discussed previously, there is no obvious difference on consumers' knowledge about luxury products with different income. Therefore, it could be demonstrated that the gap between upper middle class consumers' luxury handbags knowledge and mass middle class consumers' knowledge has been narrowed because of the information explosion in the digital age. However, due to young generations' fast understanding and application of digital devices, it is clearly shown that younger consumers are much more knowledge than their parents' generation about luxury handbags.

Furthermore, education has statistical relationship with four out of six motivations including appreciating luxury brand's culture and history, representing success and social status, showing uniqueness, and social comparison. It could be seen that education is still the main factor to differentiate the luxury handbags buying motivations of Taiyuan middle class consumers. On the other hand, age has not shown much significant relationship with consumers' luxury buying motivations. As a result, age is not an important factor to analyse middle class consumers' luxury handbags buying motivations in Taiyuan as show in Table III.

TABLE III. RESULTS OF HYPOTHESES

\begin{tabular}{|l|l|}
\hline \multicolumn{1}{|c|}{ Hypothesis } & Result \\
\hline $\begin{array}{l}\text { H1. Upper middle class consumers are more likely to purchase } \\
\text { luxury handbags because of appreciating luxury products' } \\
\text { craftsmanship and durability than mass middle class } \\
\text { consumers in Taiyuan. }\end{array}$ & Supported \\
\hline $\begin{array}{l}\text { H2. Upper middle class consumers tend to consider that } \\
\text { owners of luxury handbags are having good taste. }\end{array}$ & Supported \\
\hline $\begin{array}{l}\text { H3. Upper middle class consumers are more likely to purchase } \\
\text { luxury handbags to showing personal success and social } \\
\text { status. }\end{array}$ & Supported \\
\hline $\begin{array}{l}\text { H4. Consumers with oversea or higher education background } \\
\text { are more likely to purchase luxury handbags for self- } \\
\text { rewarding. }\end{array}$ & Supported \\
\hline $\begin{array}{l}\text { H5. Mass middle class consumers are as knowledgeable on } \\
\text { luxury handbags as consumers from upper middle class. }\end{array}$ & Supported \\
\hline
\end{tabular}

To sum up, the first three hypotheses and the last one are supported, which means they are consistent with previous literature. However, the fourth hypothesis is not supported, which indicates that for Taiyuan middle class consumers, education has no statistical relationship with the buying motivation of self-reward. 


\section{CONCLUSION}

In this research, the author has attempted to explore the Chinese consumers' luxury goods buying motivations in Taiyuan. In doing so, the author has built a theoretical framework based on Bourdieu's taste theory and compared the motivations and attitudes toward luxury consumption across different social groups, by using a statistical regression analysis. Before concluding the final results, it is worth reviewing the whole process in terms of how the author has reached the conclusions.

The research has three research questions. In order to conduct the research, this study has used a questionnaire survey and done a statistical regression analysis. The results show that the first two questions are consistent with previous literature. However, the third one does partially not fit the literature. Therefore, there are still some statistical relationships which need more exploration of the mechanisms behind them in the future research.

In this research, the main indicator of social class is income. As showed in the statistical analysis, income is a statistically significant indicator for most dependent variables, which indicates that there are still great differences between social classes in terms of luxury goods buying motivations and attitudes. This result lends the most direct support to Bourdieu's taste theory that social class is still a main determinant of individual behaviours. Also, the result is consistent with many empirical research conducted in large cities.

\section{REFERENCES}

[1] Red Luxury, Chinese Luxury Market Trends for 2015. http://red-luxury.com/trends/chinese-luxury-market-trends-for-2015$\underline{28431}$

[2] R. D. Green, "Global Luxury Trends: Innovative Strategies for Emerging Markets", Journal of Product \& Brand Management, 23[4/5], pp. 373-374, 2014.

[3] Y. Wang, S. Sun, and Y. Song, "Chinese luxury Consumers: motivation, attitude and behaviour", Journal of Promotion Management, 17, pp. 345-359, 2011.

[4] G. Sun, S. D'Alessandro and L. Johnson, Traditional culture, political ideologies, materialism and luxury consumption in China, International Journal Of Consumer Studies, 38[6], Pages: 578-585, 2014.

[5] L. Øygard, Studying food tastes among young adults using Bourdieu's theory, International Journal Of Consumer Studies, 24[3], Pages: 160$169,2000$.
[6] A. Prieur, and M. Savage, "Updating Cultural Capital Theory: A Discussion Based on Studies in Denmark and in Britain", Poetics, 39, pp. 566-580, 2011.

[7] J. E. Workman and S. Cho "Gender, Fashion Consumer Groups, and Shopping Orientation", Family and Consumer Sciences Research Journal, 40[3], pp. 267-283, 2012.

[8] Geert Hofstede. Culture's Consequences: comparing values, behaviors, institutions, and organizations across nations [2nd ed.]. Thousand Oaks, CA: SAGE Publications.

[9] K. Charmaz. Constructing Grounded Theory. London: Sage.

[10] M. Zanasi. "Frugal Modernity: Livelihood and Consumption in Republican China", The Journal of Asian Studies, 74[02], pp. 391409,2014.

[11] P. Bourdieu. Distinction: A Social Critique of the Judgment of Taste, Harvard: The Harvard University Press, 1984.

[12] H. Warner. "Fashion, Celebrity and Cultural Workers: SJP as Cultural Intermediary", Media, Culture \& Society, 35[3], pp.382-391,2013

[13] E. F. McQuarrie and B. J. Philips. "The Megaphone Effect in Social Media: How Ordinary Consumers Become Style Leaders", Marketing Intelligence Review, 6[2], pp.16, 2014

[14] K. Rafferty. "Class-based Emotions and the Allure of Fashion Consumption", Journal of Consumer Culture, 11[2], pp.239-260,2011.

[15] Antoine Hennion. "Those Things That Hold Us Together: Taste and Sociology". Cultural Sociology, Vol. 1, No. 1, 97-114. London: Sage, 2012.

[16] D. B. Holt. "Does Cultural Capital Structure American Consumption?", The Journal of Consumer Research, Vol. 25, No. 1, pp. 1-25,2010.

[17] M. Hollis and E. J. Nell. Rational Economic Man. Cambridge: Cambridge University Press, 2008

[18] T. T. Veblen. Theory of the Leisure Class: An Economic Study in the Evolution of Institutions. New York: Macmillan, 2010

[19] Y. Truong, R. McColl and P. J. Kitchen. "New Luxury Brand Positioning and The Emergence of Masstige Brands", Journal of Brand Management, 16[5], pp.375-382, 2009

[20] A. G. Woodside. "Economic Psychology and Fashion Marketing Theory Appraising Veblen's Theory of Conspicuous Consumption", Journal of Global Fashion Marketing, 3[2], pp.55-60,2012

[21] C. Amatulli and G. Guido. "Determinants of Purchasing Intention for Fashion Luxury Goods in the Italian Market", Journal of Fashion Marketing and Management, 15[1], pp.123-136,2011

[22] Hung, K.-P., Chen, A.H., Peng, N., Hackley, C., Tiwsakul, R.A. and Chou, C.-I. "Antecedents of Luxury Brand Purchase Intention", Journal of Product \& Brand Management, 20[6], pp.457-467, 2011

[23] L. J. Zhan and Y. Q. He. "Understanding luxury consumption in China: Consumer perceptions of best-known brands", Journal of Business Research, 65[2012], pp. 1452-1460,2011

[24] G. Li and Z. Kambele "Luxury Fashion Brand Consumers in China: Perceived Value, Fashion Lifestyle, and Willingness to Pay", Journal of Business Research, 65[10], pp. 1516-1522, 2011 